\title{
6 \\ Tratamiento del Capital Social en la transformación de las Cooperativas
}

\author{
Dr. Iñigo Nagore \\ Abogado-Economista \\ Profesor del Instituto de Estudios Cooperativos
}

El segundo principio cooperativo recogido en la Declaración sobre la Identidad Cooperativa formulada por la Alianza Cooperativa Internacional en su Congreso de Manchester de 23 de septiembre de 1995, recogía que en las cooperativas de primer grado los socios tienen iguales derechos de voto (un socio, un voto), y que las cooperativas de otros grados están también organizadas de forma democrática.

$Y$ el tercero, que respecto al capital los socios reciben una compensación, si la hay, limitada sobre el capital entregado como condición para ser socio y respecto a los excedentes, que se asignan a todos o algunos de los siguientes fines: el desarrollo de su cooperativa; el beneficio de los socios en proporción a sus operaciones con la cooperativa; y al apoyo de otras actividades aprobadas por los socios.

Principios reconocidos explícitamente en el artículo 1 de la Ley 27/1999, de 16 de julio, de Cooperativas (LC) y, en su esencia, en los artículos 26 (cada socio tendrá como regla general un voto, cabiendo en ciertos supuestos y con ciertos límites un voto proporcional a la actividad cooperativizada o según clases de socios), 48 (remuneración de las aportaciones) y 58.4 (retorno en proporción a la actividad cooperativizada).

Establece el artículo 69.2 de la LC, al regular la transformación de la sociedad cooperativa en sociedad civil o mercantil de cualquier clase, que la participación de los socios de la cooperativa en el capital social de la nueva entidad habrá de ser proporcional al que tenían en aquella. 
La legislación cooperativa autonómica española contempla, en los pocos casos en los que se trata la cuestión, las siguientes opciones:

-País Vasco (LCEuskadi, art. 85.5): La Asamblea General puede optar por convertir las aportaciones económicas al capital social en participaciones económicas de la nueva entidad en proporción directa que capital que tuviera desembolsado cada socio en la cooperativa, al derecho de voto que ostentaba en la misma cooperativa, o bien combinando ambos criterios.

- Valencia (LCValencia, art. 68.5): La Asamblea General acordará la distribución de las participaciones en el capital social de la nueva entidad, en proporción directa al capital desembolsado por cada socio en la cooperativa, actualizando en su caso.

- Extremadura (LCExtremadura, art. 75.b): La cuota que corresponde a cada socio o asociado en el capital social de la nueva sociedad, será proporcional a la participación que tuviera en el capital social de la sociedad cooperativa que se transforma.

Puede decirse que las posibilidades contempladas se resumen en: en proporción al capital (sea suscrito o desembolsado y actualizado o no), en proporción al derecho de voto o a ambos.

Resulta paradójico que el criterio a considerar, al transformar una sociedad personalista como la cooperativa, sea el capital. Parece que abandonando el sistema, la propia ley reguladora obligue a «pasarse» a un sistema de capitales puro, olvidando que existen otros posibles destinos transformadores y que, además, cabe modular el sistema (por ejemplo, si todos los socios tiene igual porcentaje de capital, con lo que al inicio todos los socios tendrían igual porcentaje de voto...).

En la actual regulación estatal será el capital, elemento a "sueldo» en la cooperativa, el elemento clave a la hora de estructurar el capital social de la nueva cooperativa.

Parecería más lógico que, a la vista de las diversas formas de funcionamiento de los derechos políticos y económicos en la sociedad cooperativa y en la sociedad de capital, se marcasen, en la transformación, posibilidades que permitiesen conservar el mayor número de peculiaridades o, al menos, tuvieran un punto de conexión real con la filosofía cooperativa.

Simplificando, podríamos afirmar que en una cooperativa el principal derecho político, el voto, se ejerce conforme a la filosofía un 
hombre un voto. Transportar esta filosofía a una sociedad de capital exigiría permitir a los socios igualar los capitales. Igualación que, en principio, entiendo debiera ser al alza, salvo acuerdo unánime, a modo de derecho adicional de socio de la cooperativa en la transformación, otorgado en orden a mantener su capacidad de participar en toma de decisiones. Dicho derecho debiera tener un plazo de ejecución y poder ser ejecutado total o parcialmente.

Mención aparte merecerían los socios con voto fraccionado o proporcional según la actividad realizada. Para los primeros bastaría con mantener esa proporcionalidad en el sistema expuesto y para los segundos se podía haber previsto lo que indicaré a continuación para los derechos económicos.

Por otro lado, el principal derecho económico consistiría en participar de los resultados de la cooperativa y que el mismo se realizara en atención a la actividad realizada por cada socio en la cooperativa.

Salvaguardar ese derecho en una sociedad de capitales implicaría distribuir el capital social, o al menos otorgar la opción de suscribir su ampliación para garantizar el efecto, en atención a la actividad cooperativizada realizada en un período de tiempo.

Y es que, dado que en la sociedad de capital el voto y la participación en resultados viene marcados, como regla general, por el número de acciones o participaciones, mientras que en las cooperativas uno viene por la condición de socio y el otro por la actividad realizada, con independencia en ambos casos del capital, creemos que hubiera sido más lógico atender a uno u a otro, o permitir una mezcla de ambos en vez de recurrir al capital, elemento totalmente ajeno a la filosofía cooperativa.

Inclusive, el mantenimiento de los derechos políticos podía haberse alcanzado mediante el establecimiento de un derecho a mantener el porcentaje que significaba el voto de cada socio en el voto total de la cooperativa en el capital con derecho de voto de la nueva sociedad y ajustar, en parte y cuando fuera posible, el problema de la participación en resultados a través de las acciones sin voto o de las cuentas en participación.

Se permitiría así una sociedad de capital con un funcionamiento práctico inicial más similar a una cooperativa. 
En cualquier caso, y a la vista de la actual regulación, no debe extrañar, sino que sería recomendable, una reordenación de las aportaciones sociales previa a la propia transformación.

Otro problema adicional, puede surgir de las distintas aportaciones a capital existentes, esto es, de la existencia de las aportaciones obligatorias y voluntarias (arts. 45 a 47 LC). Por un lado, el artículo 69 de la Ley no distingue entre ambas y por otro, el interés, a tenor de los derechos económicos que conllevan, que podían tener los socios para realizar aportaciones voluntarias es totalmente distinto del que pueden tener en participar en la nueva sociedad.

En conclusión, si en la cooperativa el derecho de voto y de participación en resultados se ejercita con independencia del capital, se debería haber considerado esa problemática a la hora de regular la transformación, al objeto de mantener la proporción. En cualquier caso, y con carácter previo a la transformación, podrá ser necesario reorganizar las aportaciones de los socios, en aras a mantener dicha proporcionalidad, usando la normativa cooperativa (régimen de votos y mayorías) antes de que ésta se altere al producirse la transformación. 